\title{
Anaerobic Performance and Acid-Base Balance in Basketball Players after the Consumption of Highly Alkaline Water
}

\author{
Kurylas Anna, Zając Tomasz, Jakub Chycki, Maszczyk Adam, Zając Adam* \\ The Jerzy Kukuczka Academy of Physical Education in Katowice, Department of Sports Training \\ Mikołowska 72A, 40-065 Katowice, Poland
}

*Corresponding author: Zając Adam, The Jerzy Kukuczka Academy of Physical Education in Katowice, Department of Sports Training, Mikołowska 72A, 40-065 Katowice, Poland, E-mail: a.maszczyk@awf.katowice.pl

\begin{abstract}
Many researchers have unequivocally demonstrated that water of higher $\mathrm{pH}$ has a positive effect on the human body. In terms of undertaken research, the adjustment of acid-base balance during anaerobic effort, a decrease in the concentration of free radicals as well as the improvement of connective tissue condition is of primary importance. The aim of this study was to evaluate an influence of high alkaline water consumption on anaerobic performance and acid-base balance in professional basketball players. There was evaluating changes in parameters of blood and urine in laboratory tests ( $\mathrm{pH}, \mathrm{pCO}_{2}, \mathrm{pO}_{2}, \mathrm{HCO}_{3}$ act, $\mathrm{HCO}_{3}$ std, $\mathrm{BE}$ (ecf), $\mathrm{BE}(\mathrm{B}), \mathrm{O}_{2}$ std, and $\mathrm{ctCO}_{2}$ ). The group of fourteen adults male underwent in two experimental trials, before and after six weeks hydration tested water. Statistical analysis of blood tests showed that after ingestion of alkaline water there was a significant increase of blood $\mathrm{pH}$ at rest and after anaerobic exercise. The same results were obtained in urine tests, respectively 1.30 in rest and 0.93 after physical examination. The results of the specific anaerobic endurance test revealed a significant difference in performance between the tests performed after hydrating with highly alkaline water in comparison to table water. The average improvement of results equaled $0.71 \mathrm{~s} .(\mathrm{p}=0.03)$. In conclusion the athletes hydrated with alkaline water showed a positive impact on acid-base balance with a significant increase of blood and urine $\mathrm{pH}$. The daily intake of $2.5-3.01$ of highly alkalized water delay in muscular acidosis during anaerobic exercise, as well as prevention of dehydration, and faster recovery.
\end{abstract}

Received Date: December 04, 2017

Accepted Date: January 17, 2018

Published Date: January 25, 2018

Citation: Zając, A., et al. Anaerobic Performance and Acid-Base Balance in Basketball Players after the Consumption of Highly Alkaline Water. (2018) Int J Food Nutr Sci 5(1): 134- 139.

DOI: $10.15436 / 2377-0619.18 .1754$

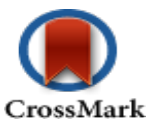

\section{Introduction}

Basketball is a team sport that involves speed, acceleration, changes of direction as well as numerous technical and tactical activities that require concentration and precision ${ }^{[1,2]}$. Actions are executed and repeated at high intensity, causing significant disturbances in acid-base equilibrium and gradual fatigue. A basketball game played at the elite level can elicit up to $90 \%$ of maximal heart rate, while blood lactate concentrations can reach $6-7 \mathrm{~m} \mathrm{~mol} / 1$ at half time and close to $8-10 \mathrm{~m} \mathrm{~mol} / 1$ after the game $\mathrm{e}^{[3,4]}$. In addition, new game rules initiated in 2000 such as the reduction of offensive possession time from 30 to $24 \mathrm{~s}$ and a limit of $8 \mathrm{~s}$ to cross the midcourt line significantly increased the pace of the game, and the physical demand on players. The physical ability to perform repeated sprints at high intensity until the end of the game plays a central role in competition and can determine the final outcome ${ }^{[5,6]}$. A crucial aspect of competitive sports includes the appropriate supply of fluids. The hydration status in professional athletes should be maintained at an optimal level, as both the lack and excess of fluid intake adversely affect exercise tolerance. The systematic maintenance of fluid balance is crucial in providing the appropriate volume of blood in vessels, and, consequently, an efficient transport of oxygen, nutrients, by-products of metabolism and heat. A frequent issue of competitive sports, including team sport games is the inadequate supply of water or other fluids. A dehydration of $1-2 \%$ may result in the lack of concentration, weakened cognitive functions, reduced efficiency and lower exercise tolerance ${ }^{[7]}$.

Copyrights: (C) 2018 Zając, A. This is an Open access article distributed under the terms of Creative Commons Attribution 4.0 International License. 
Athletes can control hydration through thirst, changes in body mass or by observing the colour of urine. However, changes in the above-named variables can be observed once dehydration has already taken place, making it impossible to prevent reduced efficiency during training or competition. Because of that fact, athletes should anticipate and prevent oncoming changes in the body. Controlling fluid intake before, during and after physical effort is of great importance to competitive athletes. Only a complex approach can ensure that an athlete will be fully hydrated for training or competition ${ }^{[8-11]}$. The issue of adequate hydration becomes even more significant when exercises at altitude ${ }^{[12]}$. An increasingly popular alternative to various sports drinks and supplements includes water with adjusted contents of minerals and $\mathrm{pH}$. The wide application spectrum of such water results from its buffering and therapeutic properties. Experimental research with alkaline water revealed its positive effect on acid-base balance, both during rest and after anaerobic effort ${ }^{[13]}$. Weidman et al revealed that water with higher $\mathrm{pH}$ ensured better rehydration after intense physical effort-induced dehydration than that provided by standard water. The foregoing conclusion was based on research involving blood viscosity tests in a randomised group of 100 adults. Alkaline water decreased blood viscosity by $6.30 \%$, which was significantly more than the result obtained with standard water $(3.36 \%)^{[14]}$. Alkaline water may also inhibit the effect of oxidative stress generated in cells during high-intensity exercise. The above mentioned favourable influence was identified using a marker enabling the determination of oxidative damage to DNA in lymphocytes, i.e. 8-oxy-2'-deoxyguanosine (8-oxo$2 \mathrm{dG})$. In contrast to water with a higher $\mathrm{pH}$, water having high contents of electrolytes did not trigger any significant chang$\mathrm{es}^{[15]}$. In addition, advantages related to alkaline water intake, include its positive effect on connective tissue. Randomised tests involving females at a pre-menopausal age revealed that the consumption of 1.51 of alkaline water per day significantly improved the mineral density of bones, increased urine $\mathrm{pH}$, and decreased the concentration of parathyroid hormone as well as that of serum C-telopeptide ${ }^{[16,17]}$. Numerous research has confirmed that water of adjustable alkalisation has antidiabetic and antiatherogenic effect by reducing the concentration of glucose in blood and $\mathrm{HbAlc}$, as well as by lowering the concentration of triglycerides, Low-Density Lipoproteins (LDL) and the concentration of total cholesterol in the blood ${ }^{[18,19]}$. In addition, alkaline water inhibits the angiogenesis of neoplasm's and has an anti-neurodegenerative effect ${ }^{[20]}$. To sum up, many research-related tests have unequivocally demonstrated that water ofhigher $\mathrm{pH}$ has a positive effect on the human body. In terms of undertaken research, the adjustment of acid-base balance during anaerobic effort, a decrease in the concentration of free radicals as well as the improvement of connective tissue condition are of primary importance $^{[21]}$.

\section{Material and Methods}

\section{Study participants}

Fourteen male competitive basketball players with an

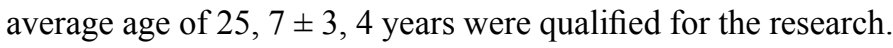
Trainings took place 5 times a week, and each session lasted 2 hours, with official games played during the weekend. The players constituted a homogenous group in regards to age, physical fitness and training experience. The average body height and body mass of the participants equaled $190.6 \pm 4.8 \mathrm{~cm}$, at $88.5 \pm$ $5.7 \mathrm{~kg}$ respectively, with $9.8 \pm 2.3$ years of training experience. All participants had valid medical examination which allowed them to take part in the experiment. The study participants consumed an caloric, mixed diet both before and during the experiment (55\% carbohydrates, $20 \%$ protein, $25 \%$ fat). The players taking part in the experiment did not take any medications or cryogenic substances, 6 weeks before and during the study. In addition, all athletes taking part in the experiment adhered to the requirement of 8 hours of sleep daily, and refrained from consuming alcohol and supplements during the experiment. Moreover, for the purpose of the study there has been an appropriate training monocycle planned which was repeated twice- before the study and during hydration.

\section{Procedure}

The research was performer in a basketball gym and in the Human Performance Laboratory of the Academy of Physical Education in Katowice, Poland. The research started with the analysis of morning urine. Then in the afternoon the same day there was a specific test of anaerobic endurance performed which was about shuttle running $6 \times 28 \mathrm{~m}$. At rest and after the physical effort the analysis of capillary blood and urine was carried out. The study participants have consumed 2, 5- 3 liters of alkaline water per 24 hours for 6 weeks. In the morning after awakening, before, during and after the training (1.5 liter) and before going to sleep. After the interference period the contestants have been put through an exercise stress tests and laboratory tests again. Figure 1 depicts the procedure of the study in detail.

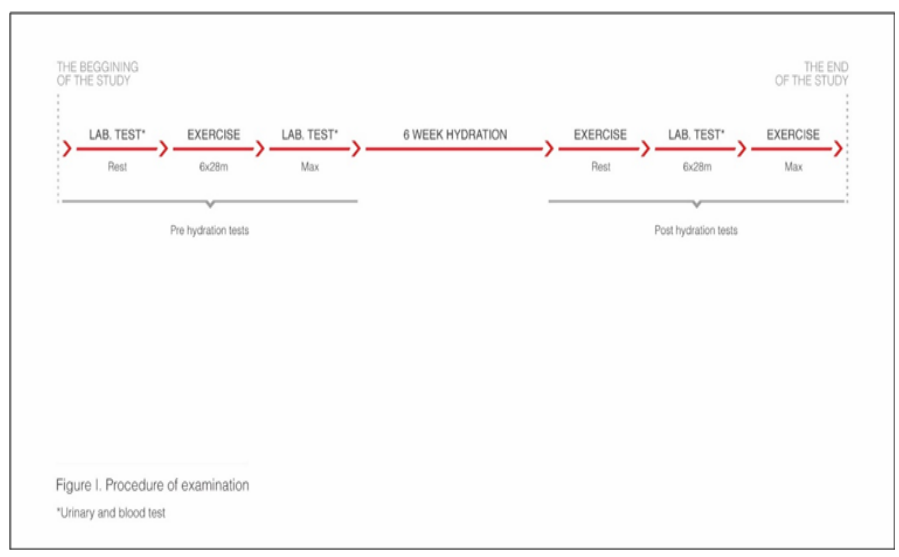

Figure 1: Procedure of the study in detail.

The players were familiarized with the procedure, possible benefits and side effects of the research, signing the consent for participation before the commencement of the study. The study received the approval of the Bioethics Committee at the Academy of Physical Education in Katowice, Poland nr 5/2015.

Alkaline water characteristics: The water used in the study was captured from a well in Humniska with a $\mathrm{pH}$ of 9, 13 which is highly alkaline compared to other commercial products. The amount of Pt was $9,4 \mathrm{mg} / \mathrm{dm}^{3}$ and carbonates $26,5 \mathrm{mg} / \mathrm{dm}^{3}$. The chemical composition is presented in detail in Table 1.

The alkaline water contained $840 \mathrm{mg} / \mathrm{dm}^{3}$ of permanent ingredients what classified it as middle mineral content. The bicarbonate ion $\mathrm{HCO}_{3}-\left(357,8 \mathrm{mg} / \mathrm{dm}^{3}\right)$ and carbonate ion 
$\mathrm{CO}_{3}{ }^{2-}\left(163,5 \mathrm{mg} / \mathrm{dm}^{3}\right)$ consisted the dominant anions. Sodium $\mathrm{Na}^{+}\left(254,55 \mathrm{mg} / \mathrm{dm}^{3}\right.$ dominated among cations. The water's characteristic was bicarbonate-carbonate-sodium $\left[\mathrm{HCO}_{3}^{-}, \mathrm{CO}_{3}^{-}\right.$, and $\left.\mathrm{Na}^{+}\right]$.

Table 1: Mineral content of alkaline water used in the study.

\begin{tabular}{|l|c|c|c|}
\hline $\mathbf{C a t i o n s}$ & $\mathbf{m g} / \mathbf{d m} \mathbf{3}^{\mathbf{3}}$ & $\mathbf{C r}$ & $\mathbf{0 , 0 0 5}$ \\
\hline $\mathbf{N a}{ }^{3+}$ & 254,55 & $\mathrm{Mo}^{6+}$ & 0,0011 \\
\hline $\mathbf{K}^{+}$ & 0,91 & $\mathrm{~V}^{5+}$ & 0,001 \\
\hline $\mathbf{L i}^{+}$ & 0,079 & $\mathrm{Zr}^{4+}$ & 0,010 \\
\hline $\mathbf{N H}^{4+}$ & 0,793 & $\mathrm{Ti}^{4+}$ & 0,02 \\
\hline $\mathbf{B e}^{2+}$ & 0,0005 & $\mathrm{As}^{3+}$ & 0,005 \\
\hline $\mathbf{C a}^{2+}$ & 10,00 & $\mathrm{Tl}^{4+}$ & 0,0001 \\
\hline $\mathbf{M g}^{2+}$ & 0,371 & $\mathrm{~W}^{6+}$ & 0,0013 \\
\hline $\mathbf{B a}^{2+}$ & 0,0099 & $\mathrm{TOTAL} \mathrm{K}^{+}$ & 266,9 \\
\hline $\mathbf{S r}^{2+}$ & 0,0344 & & \\
\hline $\mathbf{F e}^{2+}$ & 0,09 & $\mathrm{Anions}^{2+}$ & $\mathrm{mg} / \mathrm{dm}$ \\
\hline $\mathbf{M n}^{2+}$ & 0,009 & $\mathrm{~F}$ & 1,28 \\
\hline $\mathbf{A g}^{+}$ & 0,001 & $\mathrm{Cl}^{3}$ & 26,4 \\
\hline $\mathbf{Z n}^{2+}$ & 0,016 & $\mathrm{Br}^{2+}$ & 0,1 \\
\hline $\mathbf{C u}^{2+}$ & 0,017 & $\mathrm{~J}$ & 0,24 \\
\hline $\mathbf{N i}^{2+}$ & 0,001 & $\mathrm{SO}_{4}^{2-}$ & 7,81 \\
\hline $\mathbf{C o}^{2+}$ & 0,0002 & $\mathrm{HCO}_{3}-$ & 357,8 \\
\hline $\mathbf{P b}^{2+}$ & 0,0009 & $\mathrm{CO}_{3}^{2-}$ & 163,5 \\
\hline $\mathbf{H g}^{2+}$ & 0,0001 & $\mathrm{NO}_{2}$ & 3,0 \\
\hline $\mathbf{C d}^{2+}$ & 0,0003 & $\mathrm{NCV}^{2+}$ & 0,24 \\
\hline $\mathbf{S e}^{2+}$ & 0,01 & $\mathrm{CN}^{2+}$ & 0,002 \\
\hline $\mathbf{S b}^{3+}$ & 0,0011 & $\mathrm{PO}_{4}^{3-}$ & 0,7647 \\
\hline $\mathbf{A l}^{3+}$ & 0,010 & $\mathrm{TOTAL} \mathrm{A}^{-}$ & 558,1 \\
\hline
\end{tabular}

Laboratory tests: The contestants have been put through capillary blood and urine test in order to evaluate the acid-base balance of the body. The analysis has been performed at rest and after the physical effort ( 6 × 28 m shuttle run).

Blood tests: The research was carried out at the Human Performance Laboratory of the Academy of Physical Education in Katowice. Capillary blood sample was taken from contestants' index finger tips in the amount of $1 \mathrm{ml} . \mathrm{pH}, \mathrm{pCO}_{2}, \mathrm{pO}_{2}, \mathrm{HCO}-$ ${ }_{3}$ act, $\mathrm{HCO}_{3}$ std, $\mathrm{BE}$ (ecf), $\mathrm{BE}(\mathrm{B}), \mathrm{O}_{2} \mathrm{SAT}$, ctCO 2 parameters were measured. On their basis the acid-base balance of the body was evaluated before and after the physical effort as well as before and after hydration.

Urine tests: The tests were carried out at a Diagnostics Laboratory. Urine $\mathrm{pH}$, specific gravity and residue variables were evaluated. On the base of the above mentioned variables, the acid-base balance was evaluated before and after the anaerobic physical effort as well as before and after hydration.

Physical fitness test: The players performed a specific basketball anaerobic endurance test, which consisted of a $6 \times 28 \mathrm{~m}$ shuttle run (length of a basketball court) timed with photocells (Microgate, Italy). The test was preceded by a 20 min warm-up which included dribbling, shooting and the 3 man weave followed by 5 min of dynamic stretching.

\section{Statistical analysis}

Normality of distribution was verified using the Shapiro-Wilk test. All data are presented as mean \pm SD. Verifications of the differences between analyzed variables and groups were carried out using the ANOVA analysis of variance with repeated measures. Statistical significance was set at $p<0.05$. All statistical analyses were performed using Statistica 9.1 with neural network module, and Microsoft Office - Excel 2010 packets.

\section{Results}

All the measurements were carried out with greatest care, according to established procedures and methodology. The players performed both tests under similar external conditions (air temperature $25 \mathrm{C}^{\circ}$, relative humidity $65 \%$ ). The study participants rested the day before testing to minimize the effects of fatigue. In order to minimalize the influence of dependent variables on the tested variables, a specific 6-week training mesocycle was programmed and repeated twice during the experiment. During the experiment the participants did not take any supplements, medications, did not smoke and refrained from alcohol. Throughout the study the basketball players used a mixed, isocaloric $(3255 \pm 676 \mathrm{kcal} / \mathrm{d})$ diet $(55 \% \mathrm{CHO}, 20 \%$ Pro and $25 \%$ Fat), which was similar to the one adopted before the study. One player was eliminated from the study due to injury which prevented him from training and performing the anaerobic exercise protocol.

Statistical analysis of blood tests showed that after ingestion of alkaline water there was a significant increase of blood $\mathrm{pH}$ at rest (0.192), $\mathrm{pCO}_{2}$ (7.459), $\mathrm{HCO}_{3}$ act (12.977), $\mathrm{HCO}_{3}$ std (11.615), BE(ecf) (-9.390), BE(B) (-8.701) and $\mathrm{ctCO}_{2}$ (13.191) (Table 1). A comparison of other blood variables, such as $\mathrm{pO}_{2}$ and $\mathrm{O}_{2}$ SAT did not show any statistically significant differences. After the $6 \times 28 \mathrm{~m}$ anaerobic exercise test blood evaluations revealed a significant increase in blood $\mathrm{pH}(0.15$ with $\mathrm{F}=4.459$ and $\mathrm{p}=0.002)$, what did not occur when the players drank table water. No significant changes were observed in other blood variables $\left(\mathrm{pO}_{2}, \mathrm{pCO}_{2}, \mathrm{HCO}_{3}\right.$ act, $\mathrm{HCO}_{3}$ std, $\mathrm{BE}$ (ecf), $\mathrm{BE}(\mathrm{B}), \mathrm{ctCO}_{2}$ and $\mathrm{O}_{2} \mathrm{SAT}$ ) in the group of basketball players drinking table water during the 6 week intervention period.

Table 2: Results of statistical analysis (ANOVA) of blood after hydration with alkaline water at rest.

\begin{tabular}{|c|c|c|}
\hline Variables & $\mathbf{F}$ & $\mathbf{P}$ \\
\hline pH & 280,271 & $0,001 *$ \\
\hline $\mathrm{pCO}_{2}[\mathrm{mmHg}]$ & 37,874 & $0,001 *$ \\
\hline $\mathrm{pO}_{2}[\mathrm{mmHg}]$ & 3,996 & 0,055 \\
\hline $\mathrm{HCO}_{3}$ act $[\mathrm{mmol} / \mathrm{L}]$ & 384,810 & $0,001 *$ \\
\hline $\mathrm{HCO}_{3}$ std $[\mathrm{mmol} / \mathrm{L}]$ & 547,292 & $0,001 *$ \\
\hline BE(ecf) $[\mathrm{mmol} / \mathrm{L}]$ & 476,883 & $0,001 *$ \\
\hline $\mathrm{BE}(\mathrm{B})[\mathrm{mmol} / \mathrm{L}]$ & 503,360 & $0,001 *$ \\
\hline $\mathrm{O}_{2}$ SAT $[\%]$ & 0,063 & 0,803 \\
\hline $\mathrm{stCO}_{2}[\mathrm{mmol} / \mathrm{L}]$ & 366,184 & $0,001 *$ \\
\hline
\end{tabular}

* statistically significant differences

The initial urine test results, before hydration with alkaline water did not reveal significant differences before and after the intense physical effort. However, the intergroup analysis 
indicated a significant increase of urine $\mathrm{pH}$ at rest (1,301 with $\mathrm{F}$ $=39,942$ and $\mathrm{p}=0.0001)$ and directly after the physical effort, after the 6 -week hydration with alkaline water $(0.933$ with $\mathrm{F}=$ $19,601$ and $p=0.0001)$. Significant changes were also noticed during the comparison of urinary specific gravity at rest $(\mathrm{F}=$ 5,446 and $p=0.0270$ ). After hydration with alkaline water there was a significant decrease in urinary specific gravity $(-0.006)$ (Table 2).

The results of the specific anaerobic endurance test $(6$ x $28 \mathrm{~m}$ shuttle) revealed a significant difference in performance between the tests performed after hydrating with highly alkaline water in comparison to table water. The average improvement of results equaled $0.71 \mathrm{~s}$. With $\mathrm{F}=5.256$ and $\mathrm{p}=0.03$.

\section{Discussion}

The conducted experiment concerning the effect of alkalised water on acid-base, and water-electrolyte balance of basketball players revealed positive changes confirmed by blood and urine $\mathrm{pH}$-related tests). The values obtained prior to and following the exercise protocol were significantly improved after the period of alkalised water-based hydration. The specific exercise protocol was characterised by a predominance of anaerobic processes activating metabolic acidosis. Results of the specific basketball endurance test $(6 \times 28 \mathrm{~m})$ improved by $0.71 \mathrm{~s}$ in comparison to those obtained in the pre-hydration period.

Players participating in the tests constituted a homogenous group. They were characterised by similar age, training experience, and the level of physical fitness. The anthropometric variables of tested individuals differed accordingly which corresponded to the specific nature of basketball where, e.g. playmakers are characterised by lower height and lower body mass (180 - $190 \mathrm{~cm}$ and $80-85 \mathrm{~kg}$ respectively), whereas pivot players are significantly taller and heavier $(200-210 \mathrm{~cm}$ and $95-115 \mathrm{~kg}$ respectively). Before the study commenced, the players participating in the experiment completed a 6 -week conditioning period. During the experiment the players completed 5 training units a week, each lasting 90 - $120 \mathrm{~min}$, where 2 training sessions were characterised by high intensity, specific basketball drills, during which exercise metabolism was dominated by anaerobic glycolysis, with a significant disturbance of acid-base balance. Besides the 5 training units the study participants played an official league game on Saturdays.

One of the novel aspects of this research included the use of highly alkalized water ( $\mathrm{pH} 9.13)$. Another novel element of the experiment was the time of intervention amounting to 6 weeks, and the amount of consumed water (2.5 - 3 litres/d). This facilitated the course of adaptive changes, and increased the accuracy and reliability of the evaluations. The study protocol also involved the monitoring of the players' diet to minimise its impact on experimental results. During the 6-week intervention period the basketball players were on a mixed diet $(55 \%$ $\mathrm{CHO}, 20 \%$ Pro and $25 \%$ Fat), where the average caloric value amounted to $3285 \pm 688 \mathrm{kcal} / \mathrm{d}$ and was similar to the food intake preceding the experiment. The caloric diversity resulted primarily from significantly different body mass of the players and not from energy expenditure (similar in terms of all study participants).

The results obtained in our study are mostly confirmed in the available literature regarding the use of alkalized water, al- though few studies have been conducted on competitive athletes involved in intense anaerobic exercise ${ }^{[13,14,23]}$.

Heil[17] performed an experiment involving a group of 38 untrained volunteers and water having a $\mathrm{pH}$ of 10.0. The daily intake of the alkalised water was individualized and, in the experimental group, amounted to 2.2 - 2.4 litres per day. After a 4-week intervention it was possible to observe a significant increase in blood and urine $\mathrm{pH}$ of participants ingesting alkalised water in comparison with values registered for the control group. An average increase in blood $\mathrm{pH}$ after the physical effort amounted to 0.15 , whereas that of urine amounted to 0.93 . The tests also revealed an increase in blood osmolality and a decrease in urine osmolality. Interesting results were also obtained by Ostojic and Stojanovic ${ }^{[22]}$, who tested water having a $\mathrm{pH}$ of 9.3 in a group of 52 physically active men. The volunteers consumed 2 litres of water per 24 hours for a period of 2 weeks. The amount of water was smaller and the intervention period was shorter than those used in the tests described in this work. As a consequence of drinking Hydrogen Rich Water (HRW), significant increases in blood $\mathrm{pH}$ and bicarbonates were registered. After 2 weeks of administration, the HRW group had higher levels of fasting $\mathrm{pH}$ than the placebo group $(7.44 \pm 0.10$ vs. $7.38 \pm 0.09, p=0.03)$, and a higher concentration of bicarbonates (30.5 \pm 1.9 vs. 27.1 $\pm 1.3 \mathrm{~m} \mathrm{Eq} / \mathrm{L}, \mathrm{p}<0.001)$. The intake of HRW significantly increased post exercise $\mathrm{pH}$ from $7.39 \pm 0.15$ to $7.46 \pm 0.11$ (p $=0.03$ ) after intervention. Results confirming the advantageous effect of water having higher $\mathrm{pH}$ values were obtained by ${ }^{[13]}$, who observed a group of 36 soccer players consuming 4 litres of variously mineralised water (highly mineralized water $\mathrm{pH} 6.1$, low mineralized water $\mathrm{pH} 8$ and table water $\mathrm{pH} 5$ ). In spite of a relatively short intervention time the results obtained in the above-named experiment were similar to those reached in our study. The group consuming the water characterised by the highest alkalisation revealed a significant increase in urine $\mathrm{pH}$ (by 0.5 ) after anaerobic effort following the period of hydration, and a decrease in the specific weight of urine. The groups consuming highly mineralised and table water did not reveal significant changes. When comparing the results obtained within this study and those referred to in reference publications it was possible to observe positive effects resulting from the consumption of water having higher $\mathrm{pH}$ on variables characterizing the acid-base balance of the body. Studies involving both, untrained individuals and competitive athletes revealed an increase in blood and urine $\mathrm{pH}$ after the hydration with alkalised water, as well as a decrease in specific weight of urine. The authors found it interesting that positive changes were obtained regardless of the duration of the intervention.

Numerous researches demonstrate that a common issue concerning basketball players is connected with the fact that they play games in a state of dehydration. Seventy five percent of young elite basketball players at the FIBA Europe U20 Championship started the tournament with a dehydration of $883 \mathrm{~m}$ Osmol/bm. In turn, tests involving adult NBA players during the summer basketball league revealed that $52 \%$ of tested individuals started games in the state of dehydration (USG $>1,020$ ) ${ }^{\text {[24] }}$. During official competition in basketball the loss of fluids is significant, and can reach 2 litres per 20 minutes of the game. Tests performed by Osterberg et al., ${ }^{[25]}$ revealed that players lost on the average 2.2 litres during a game lasting 21-40 minutes. Specific individual recommendations concerning the intake of 
fluids should be calculated based on sweat rates, sport dynamics, and individual tolerance. Some authors suggest a general rehydration protocol for basketball players: $200 \mathrm{~mL}$ at quarter breaks, $400 \mathrm{~mL}$ at half time and $100 \mathrm{~mL}$ at one timeout/half ${ }^{[24]}$. However, certain tests indicate the lack of appropriate supply of fluids during the game in spite of players having unlimited access to them. There are reports indicating that the fluid demand in competitive basketball is only replaced in 50 to $70 \%$ of the need needs ${ }^{[26]}$. The most sensitive method enabling the determination of hydration is the measurement of plasma osmolality, the proper value of which amounts to $280-290 \mathrm{~m} \mathrm{Osmol} / \mathrm{kgbm}$. The body dehydration increases along with plasma osmolality values. An increase in osmolality by a mere $1 \%$ impedes the activation of compensation mechanisms, i.e. the secretion of ADH and the intensification of thirst aimed to prevent dehydration ${ }^{[27,28]}$. Metabolism during anaerobic exercises is significantly affected by the acid-base balance of the organism. Variables enabling the assessment of fluctuation include the level of lactate and bicarbonate in the blood, blood and urine $\mathrm{pH}$ as well as the saturation of blood with oxygen and carbon dioxide ${ }^{[29]}$. The reduction of acidification during and after anaerobic effort increases the efficiency of exercises through the intensification of lactate utilisation and an increase in the production of ATP ${ }^{[30]}$. The effect of metabolic alkalosis can be obtained by the use of sodium bicarbonate and B-alanine supplements, which was demonstrated in numerous researches ${ }^{[31,32]}$. Recent reports, as well as the results of our study indicate that drinking alkalised water may have a positive effect on acid-base balance and in consequence improve high intensity exercise performance. However, this problem requires further observation to optimise the recommended doses and hydration time.

The results of this experiment confirm that ingesting water with a higher $\mathrm{pH}$ favourably influences acid-base balance and hydration of competitive athletes, in this case semi-professional basketball players. The daily intake of $2.5-3.01$ of highly alkalized water brings about several advantages including, a delay in muscular acidosis during anaerobic exercise, as well as prevention of dehydration, and faster recovery. Importantly, favourable properties of alkalised water are not limited to athletes and exercise. Regular consumption of alkalised water has several clinical advantageous, such as the treatment of gout, decreased oxidative stress, slowing down of osteoporosis, regulating blood glucose levels in diabetes, as well as anti-atherogenic and antineoplastic effects ${ }^{[1,33-35]}$.

Conflict of Interest: Authors have no conflict of interest to declare.

Acknowledgements: This work was supported by the Ministry of Science and Higher Education of Poland under Grant NRSA3 03953 and NRSA4 04054.

\section{References}

1. Ben, A.N., El, F.S., El, A.J., et al. Time-motion analysis and physiological data of elite under-19-year-old basketball players during competition. (2007) Br J Sports Med 41(2): 69-75.

Pubmed | Crossref| Others

2. Car, H.M., Co, M.J., Go, C.E., et al. Age-related variation of anaerobic power after controlling for size and maturation in adolescent basketball players. (2011) Ann Hum Biol 38(6): 721-727.

Pubmed | Crossref | Others

3. Ben, A.N., Castagna, C., Jabri, I., et al. Activity profile and physiological requirements of junior elite basketball players in relation to aerobic-anaerobic fitness.( 2010) J Strength Cond Res24(9): 2330-2342. Pubmed | Crossref| Others

4. Matthew, D., Delextrat, A. Heart rate, blood lactate concentration, and time-motion analysis of female basketball players during competition. (2009) J Sports Sci 27(8): 813-821.

Pubmed | Crossref $\mid$ Others

5. Mokou, E., Nikolaidis, P.T., Apostolidis, N. Repeated sprinting ability in basketball players: A brief review of protocols, correlations and training interventions. (2016) J Phys Edu Sport 16(1): 217 - 221.

Pubmed | Crossref| Others

6. Lyons, M., Al-Nakeeb, Y., Nevill, A. The impact of moderate and high intensity total body fatigue on passing accuracy in expert and novice basketball players. (2006) J Sports Sci Med 5(2): 215-227.

Pubmed | Crossref| Others

7. Castro-Sepúlveda, M., Cerda-Kohler, H., Pérez-Luco, C., et al. EL estado de hidratación después del ejercicio afecta la tasa metabólica basal y la variabilidad de la frecuencia cardiaca. (2015) Nutr Hosp 31(3): 1273-1277

Pubmed | Crossref | Others

8. Roberts,W.O. Fluid replacement for sports safety and performance .(2012) Int Sport J Off J FIMS (International Fed Sport Med 13(2): 39-42.

Pubmed | Crossref $\mid$ Others

9. Armstrong, L.E., Pumerantz, A.C., Fiala, k.A., et al. Human hydration indices: Acute and longitudinal reference values. (2010) Int J Sport Nutr Exerc Metab 20(2): 145-153.

Pubmed | Crossref | Others

10. Baillot, M., Hue, O. Hydration and thermoregulation during a half-ironman performed in tropical climate. (2015) J Sport Sci Med 14(2): 263-268.

Pubmed |Crossref| Others

11. Armstrong, L.E., Ganio, M.S., Klau, J.F., et al. Novel hydration assessment techniques employing thirst and a water intake challenge in healthy men. (2014) Appl Physiol Nutr Metab 39(2): 138-144 Pubmed | Crossref | Others

12. Michalczyk, M., Czuba, M., Zydek, G., et al. Specific dietary recommendations during altitude training in cycling. (2016) Nutrients 8(6): 377.

Pubmed | Crossref $\mid$ Others

13. Chycki, J., Zając, T., Maszczyk, A., et al. The effect of mineral-based alkaline water on hydration status \& the metabolic response to short-Term anaerobic exercise. (2017) Biol Sport 34(3): 255-261

Pubmed | Crossref | Others

14. Weidman, J., Holsworth, R.E., Brossman, B., et al. Effect of electrolyzed high-pH alkaline water on blood viscosity in healthy adults. (2016) J Int Soc Sports Nutr 13: 45

Pubmed | Crossref | Others

15. Koyama, T., Makita, M., Shibata, N., et al. Influence of oxidative and osmotic stresses on the structure of the cell wall mannan of Candida albicans serotype A. (2009) Carbohydr Res 344(16): 2195-2200 Pubmed | Crossref | Others

16. Brancaccio, P., Limongelli ,F., Paolillo, I., et al. Supplementation of Acqua Lete ${ }^{\circ}$ (Bicarbonate Calcic Mineral Water) improves hydration status in athletes after short term anaerobic exercise.(2012) J Int Soc Sports Nutr 9(1): 35 
Pubmed|Crossref | Others

17. Heil, D.P. Acid-base balance and hydration status following consumption of mineral-based alkaline bottled water. (2010) J Int Soc Sports Nutr.

Pubmed | Crossref | Others

18. Mousa, H.A. Health effects of alkaline diet and water, reduction of digestive-tract bacterial load, and earthing. (2016) Altern Ther Health Med 1: 24-33

Pubmed | Crossref | Others

19. Ignacio, RMC., Joo, K.B., Lee, K.J., Clinical effect and mechanism of alkaline reduced water. (2012) In: Journal of Food and Drug Analysis 20(1): 394-397.

Pubmed |Crossref| Others

20. Shirahata, S., Hamasaki, T., Teruya, K., Advanced research on the health benefit of reduced water. (2012) Trends Food Sci Technol 23(2): 124-131

Pubmed |Crossref $\mid$ Others

21. Wiecek, M., Maciejczyk, M., Szymura ,J., et al. Changes in oxidative stress and acid-base balance in men and women following maximal-intensity physical exercise. (2015) Physiol Res 64(1): 93-102.

Pubmed |Crossref| Others

22. Ostojic, S.M., Stojanovic, M.D. Hydrogen-rich water affected blood alkalinity in physically active men. (2014) Res Sport Med 22(1): 49-60

Pubmed |Crossref | Others

23. Kurylas, A., Zajac, T., Zydek, G., et al. The Effectiveness of Alkaline Water in Hydrating Athletes. (2017) J of nutritional Health \& Food Sci 5(2): 1-4

Pubmed | Crossref | Others

24. Vukašinović-Vesić, M., Andjelković, M., Stojmenović, T., et al. Sweat rate and fluid intake in young elite basketball players on the FIBA Europe U20 Championship. (2015) Vojnosanit Pregl 72(12): 1063-1068 Pubmed |Crossref| Others

25. Osterberg, K.L., Horswill, C.A., Baker, L.B., Pregame urine specific gravity and fluid intake by national basketball association players during competition.(2009) J Athl Train 44(1): 53-7

Pubmed | Crossref| Others

26. Carvalho, P., Oliveira, B., Barros, R., et al. Impact of Fluid Restriction and ad Libitum Water Intake or an $8 \%$ Carbohydrate-Electrolyte Beverage on Skill Performance of Elite Adolescent Basketball Players. (2011) Int J Sport Nutr Exerc Metab 21: 214-221

Pubmed | Crossref | Others
27. Oppliger, R.A., Magnes, S.A., Gisolfi, C.V., et al. Accuracy of urine specific gravity and osmolality as indicators of hydration status. (2005) Int J Sport Nutr Exerc Metab 15(3): 236-251

Pubmed |Crossref|Others

28. Jéquier, E., Constant, F. Water as an essential nutrient: The physiological basis of hydration. (2010) Eur J Clin Nutr 64(2): 115-123

Pubmed |Crossref|Others

29. Hanon, C., Rabate, M., Thomas, C. Effect of Expertise on Postmaximal Long Sprint Blood Metabolite Responses. (2011) J Strength Cond Res 25(9): 2503-2509

Pubmed | Crossref | Others

30. Sahlin, K. Muscle Energetics during Explosive Activities and Potential Effects of Nutrition and Training. (2014) Sports Medicine 44(2): 167-173

Pubmed | Crossref| Others

31. Price, M.J., Simons, C. The effect of sodium bicarbonate ingestion on high-intensity intermittent running and subsequent performance. (2010) J Strength Cond Res 24(7): 1834-1842

Pubmed |Crossref|Others

32. Caruso, J., Barbosa,A., Perry, R., et al. $\beta$-Alanine's impact on exercise and blood lactate values incurred from repetitive supramaximal activity. (2014) Isokinet Exerc Sci

Pubmed | Crossref | Others

33. Day, R.O., Liauw, W., Tozer, L.M., et al. A double-blind, placebo-controlled study of the short term effects of a spring water supplemented with magnesium bicarbonate on acid/base balance, bone metabolism and cardiovascular risk factors in postmenopausal women. (2010) BMC Res Notes 28(3): 180 Pubmed | Crossref|Others

34. Schwalfenberg, GK. The alkaline diet: Is there evidence that an alkaline $\mathrm{pH}$ diet benefits health? (2012) J Environ Public Health Pubmed | Crossref $\mid$ Others

35. Stanisław, Pop., Adam, Zając., Miłosz,Czuba., et al. The effects of terminating creatine supplementation and resistance training on naerobic power and chosen biochemical variables in male subjects. (2008) J Hum Kinet 20: 99-110. Pubmed | Crossref | Others
Online ISSN: 2377-0619

Journal Title: International Journal Food and Nutritional Science Journal Short Name: Int J Food Nutr Sci
Ommega Online Publishers

E-mail: editor.foodscience@ommegaonline.com

Website: www.ommegaonline.org 